\title{
De la explotación de la madera a la explotación del paisaje y de la naturaleza conservada: desarrollo capitalista y producción del espacio en la cordillera austral chilena'
}

\section{From the exploitation of the wood to the exploitation of the landscape and the conserved nature: capitalist development and production of space in southern Chilean Andes}

\author{
Luis Fernando De Matheus e Silva² (1)
}

\begin{abstract}
RESUMEN
Teniendo como referencia lo que denominamos microrregión forestal-cordillerana de Panguipulli, buscamos interpretar los cambios en la producción capitalista del espacio en la cordillera austral chilena, enfatizando las diferentes formas por las cuales sus características geográficas vienen siendo valoradas e incorporadas a las redes de acumulación de capital - sobre todo en las últimas cuatro décadas - en un movimiento que tiende a ir de la explotación de la madera nativa hacia la explotación del paisaje y de la naturaleza conservada. Basándose en informaciones y datos levantados por medio de investigación documental y bibliográfica, así como de observaciones realizadas en trabajos de campo, analizamos esas transformaciones, desde una perspectiva teórica anclada en la tradición marxista, relacionándolas a las mutaciones experimentadas en las formas de extraer renta territorial. Sustentamos que hay en curso hoy, un proceso dialectico de diversificación de rentas monopolísticas, y de monopolización del territorio, que complejiza aún más la trama geográfica del medio rural regional.
\end{abstract}

Palabras clave: región; capitalismo; producción del espacio; naturaleza; paisaje; renta de la tierra.

\section{ABSTRACT}

In reference to what we name as the microrregión forestal-cordillerana de Panguipulli, we seek to understand the changes in the capitalist production of space in the southern Chilean Andes, emphasizing the different forms that geographical characteristics settings become valued and incorporated into the networks of capital accumulation - especially over the last four decades - in a movement that tends to go of the exploitation of the nati-

Artículo elaborado gracias al apoyo del proyecto postdoctorado FONDECYT 2017 3170103. "El negocio de lo prístino: Las consecuencias socioespaciales de la comodificación de la naturaleza y del paisaje en la zona lacustre-andina de Los Ríos".

Docente de Geografía Humana del Instituto de Ciencias de la Tierra de la Universidad Austral de Chile (ICT UACH). Investigador del Núcleo de Estudios Interdisciplinarios en torno a la Desigualdad y Derechos Humanos (DESDEH - UACH). Contacto: luis.dematheus@uach.cl 
ve wood towards the exploitation of the landscape and of the preserved nature. Based on information and data collected through documentary and bibliographic research, as well as observations made in field works, we analyse these transformations from a theoretical perspective anchored in the Marxist tradition, linking them to the mutations experienced on the ways of extracting land rent. We sustain that there is a dialectical process of diversification of monopolistic rents, and a monopolization of the territory, which complicate furthermore the geographical structure of rural space.

Keywords: region; capitalism; production of space; nature; landscape; land rent.

\section{Delimitando el problema y la escala espacio-temporal del análisis: la microrregión forestal-cordillerana de Panguipulli}

El objetivo del presente artículo es interpretar los cambios en la producción capitalista del espacio en la cordillera austral chilena, relacionando este proceso con las diferentes formas por las cuales sus características geográficas vienen siendo valoradas e incorporadas a las redes de acumulación de capital. Como referencia, es utilizada la aquí denominada microrregión forestal-cordillerana de Panguipulli: recorte espacial cuyos límites, a groso modo, se expanden desde la ciudad de Panguipulli hacía la frontera con Argentina, siendo delimitados, al norte, por el Lago Calafquén y, al sur, por el Lago Ranco, en la divisa con el Parque Nacional Puyehue. Ahora bien, es preciso dejar claro desde un inicio, lo que se quiere decir cuando se usa el concepto de región, al recortar (arbitrariamente) esta porción del espacio cordillerano de sur de Chile.

En ese sentido, se parte del supuesto que la región no es un constructo estático, inmutable y que existe a priori, mucho menos una simple unidad administrativa. Se trata de un proceso dinámico de diferenciación espacial, engendrado por la lógica del desarrollo geográfico desigual (Correa, 2003; Harvey, 2004) y la división socioespacial del trabajo (Massey, 1978). Considerada a la luz del materialismo histórico-geográfico, la región es entendida como una configuración geográfica que logra, durante algún tiempo, cierta estabilidad y grado de coherencia estructural, en términos de producción, distribución, intercambio y consumo (Harvey, 2004). "Las fronteras de este tipo de regiones son siempre borrosas y porosas, pero los flujos que se entrelazan en ellas producen la suficiente coherencia estructural como para distinguir el área geográfica en cuestión de todas las demás áreas de su misma economía nacional" (Harvey, 2004: 89).

Sin embargo, la coherencia estructural no puede ser reducida simplemente a lo económico, por lo que se debe considerar también el papel activo desempeñado por las actitudes, valores culturales, ideologías, creencias, y mismo afiliaciones políticas y religiosas de aquellos que la construyen. Se trata, por lo tanto, de una articulación espacial contradictoria y compleja, moldeada por cohesiones de dominancia socioeconómica, política y/o simbólico-cultural, en una dialéctica en la cual el imaginario y la construcción simbólica moldean lo vivido, al paso que las relaciones concretas de producción alimentan sus configuraciones simbólicas (Haesbaert, 2010).

Utilizando esas premisas, la microrregión forestal-cordillerana de Panguipulli es definida como una construcción abstracta y a la vez concreta: un "arte-facto" (arte + dato), que se encuentra en el cruce de un hecho y de un artificio (Haesbaert, 2010). Es decir, es una abstracción intelectual 
cuyos límites son delimitados por criterios y objetivos específicos, definidos según las necesidades de la investigación. Asimismo, este recorte tiene como base la naturaleza material-funcional de las practicas económico-políticas por las cuales el Estado, el capital y los grupos y/o clases sociales han apropiado y producido (de modo desigual, combinado y contradictorio) aquella porción del espacio, considerando las identidades surgidas y reproducidas a lo largo de la historia. En ese sentido, se puede dividir la geografía histórica de la microrregión estudiada, destacando cinco períodos clave que son eventos ${ }^{3}$ definidores para la construcción y la reconstrucción de su coherencia estructural.

El primer momento tiene inicio en la segunda mitad del siglo XIX, con la expansión (y la reorganización) de las fronteras capitalistas sobre los antiguos territorios mapuches-huilliches, y la imposición del régimen de propiedad privada al interior de los mismos. El segundo va del comienzo del siglo XX hasta mediados de los años 1960, y corresponde a la consolidación de la industria maderera local, actividad que por casi un siglo se constituyó en el principal motor de la economía de toda la cordillera de Valdivia.

El desarrollo de la actividad forestal-maderera engendró una clase trabajadora local (superexplotada) que, poco a poco, pasó a tomar consciencia de su condición y, una vez organizada, empezó a trabar una intensa lucha social y laboral con los latifundistas-capitalistas, especialmente entre fines de 1960 y el inicio de la década de 1970, culminando con la creación del Complejo Forestal y Maderero Panguipulli. Estos años configuran el tercer momento clave para la construcción de aquella regionalidad.

El cuarto momento empieza luego después del golpe cívico-militar de 1973 y dura hasta fines de los años 1980. Dentro de un escenario dictatorial de crisis capitalista y de franca decadencia de la industria maderera, la microrregión pasó por un período de intensa violencia, y variados mecanismos de acumulación por desposesión fueron puestos en marcha, abriendo camino para la ascensión de la quinta y más nueva etapa del desarrollo capitalista local, iniciada en la década de 1990.

Teniendo como contexto la vuelta de la democracia, la urbanización de la sociedad, y el acomodamiento del modelo económico impuesto durante la dictadura, las características naturales y paisajísticas de la cordillera austral pasaron a adquirir otros valores de uso, estimulando la territorialización de nuevas actividades económicas, como los negocios vinculados al turismo y a la conservación ambiental. Este momento marca un profundo cambio en la coherencia estructural microrregional, en el cual la explotación maderera fue dando lugar a la explotación del paisaje, como el principal impulsor del crecimiento económico.

En este artículo, son exploradas las transformaciones en la coherencia estructural microrregional, vinculándolas a las mutaciones experimentadas en las formas de extraer renta territorial. Para realizar esta discusión, se parte de la realidad inmediata, captada sobre todo por medio de las informaciones entregadas por diferentes estudios sobre el desarrollo capitalista en la cordillera de Panguipulli, especialmente aquellos emprendidos por Bize (2017), Alfaro (2016), Cardyn (2017), Ruiz; Arrese \& Marchini (2016), Skewes et al (2011). También fueron incorporados datos provenientes de la Comisión Verdad Histórica y Nuevo Trato con los Pueblos Indígenas (2008),

Según Milton Santos (2002), el evento es el resultado de una serie de vectores, conducido por un proceso que altera el medio preexistente, atribuyéndole nuevas funciones. 
y del Comité Memoria Neltume (2013). Asimismo, fueron explorados archivos digitales, páginas web, entrevistas y reportajes.

De esta manera, para una comprensión más atenta de los contradictorios procesos de transformación socioespacial experimentados en aquel punto especifico de la cordillera, fueron realizadas incursiones a terreno entre 2017 y 2018, recorriendo Panguipulli, Neltume y Puerto Fuy. En esas ocasiones, además de observar y registrar cómo esos procesos se materializan espacialmente, fueron efectuadas entrevistas con diferentes actores sociales locales, de modo de entender mejor los conflictos relacionados a la transformación del paisaje y de la naturaleza en valiosas mercancías. Esos trabajos de campo también sirvieron para reunir las informaciones necesarias a la construcción de los mapas presentados en el presente texto: 1) el mapa de la microrregión, destacando las tierras que pertenecían al Complejo Forestal Maderero de Panguipulli (COFOMAP), durante el auge del funcionamiento de esta empresa; $y, 2$ ) el mapa de los nuevos usos del espacio microrregional.

Esas cartografías fueron trabajadas juntamente con la geógrafa Francisca Santana, con base al software ArcGIS 10.5, usando los límites administrativos y un modelo de elevación digital (DEM) para enfatizar el relieve. Los límites de la microrregión fueron trazados a partir de la georreferenciación de los antiguos fundos que componían el COFOMAP. Además, fueron georreferenciados los usos del suelo actuales, destacando las áreas de Conservación del Servicio Nacional de Áreas protegidas (SNASPE), las iniciativas privadas de conservación (con destaque para la reserva Huilo Huilo), los circuitos turísticos, y la red vial.

En lo que refiere a la interpretación teórica de los cambios en la producción capitalista del espacio en la microrregión, esta tiene sus raíces en la tradición critica, más específicamente marxista, sustentándose en diferentes autores que - a partir del pensamiento de Marx - vienen discutiendo, de modo creativo y no ortodoxo, temas vinculados al desarrollo geográfico desigual, a la producción capitalista del espacio, a la renta de la tierra, y a la transformación en mercancía (y en espectáculo) del paisaje y de la naturaleza conservada. Entre ellos, se destacan Harvey (1990, 2009), Lefebvre (2013), Santos (2002), Smith (2010), Alessandri Carlos (2001), Katz (1998), Diegues (2001), Moraes (2005), Oliveira (2007), Moreira (1995), y Arantes (2010).

Al final, se espera entregar elementos teóricos y empíricos que ayuden a comprender cómo viene operando el actual movimiento de resignificación del espacio rural de la cordillera austral chilena, en el cual sus características ecológicas y paisajísticas sirven para fomentar la apertura de nuevas fronteras para la expansión capitalista al su interior.

\section{La microrregión forestal de Panguipulli durante los años de la explotación de la madera (1900-1980)}

\section{Conformación y modernización del territorio durante los años de con- solidación de la industria forestal-maderera (1900-1960)}

La etapa inicial del desarrollo de la industria forestal-maderera microrregional tuvo lugar entre fines del siglo XIX y la primera mitad del siglo XX, cuando "la explotación forestal tomó un rol cen- 
tral para la consolidación del Estado" (Farris \& Martinez, 2019: 30). En aquel momento, las fronteras capitalistas se expandieron hacia los antiguos territorios mapuches ubicados en la cordillera austral chilena, en un proceso de acumulación primitiva (Marx, 2013) que segregó a los pueblos originarios en reducciones, alienando las tierras consideradas más productivas, traspasándolas a las manos de unos pocos capitalistas-latifundistas, deseosos de extraer renta territorial por medio de la explotación del bosque nativo. Como resultado, toda una configuración geográfica funcional a la actividad maderera fue siendo erigida, de modo de "potenciar la acumulación progresiva de capital en una escala creciente" (Harvey, 2009: 265). Es precisamente a partir de este instante que comienza a ser configurada la coherencia estructural de la microrregión forestal-cordillerana de Panguipulli.

De ese modo, mientras nuevas tierras iban siendo puestas a producir, aumentaba el número de infraestructuras inscritas en el paisaje, como galpones, edificios fabris, núcleos residenciales, obras para el abastecimiento de agua, generación eléctrica, medios de transporte y vías de circulación. Parte considerable de estas infraestructuras de capital fijo fue construida y operada por los propios capitalistas, que necesitaban equipar el espacio y transformarlo para poder realizar el valor.

No obstante, es importante tener en cuenta que para dinamizar y modernizar la producción forestal-maderera regional, el Estado ${ }^{4}$ jugó un rol crucial, especialmente por medio de agencias y empresas públicas como la Corporación de Fomento de la Producción (CORFO) ${ }^{5}$ y la Empresa de los Ferrocarriles del Estado (EFE) ${ }^{6}$. Gracias a todos esos esfuerzos, a fines de la década de 1950, 250 aserraderos operaban en toda la provincia de Valdivia, tornándola una de las más importantes provincias madereras del país, con cerca del 40\% de la producción nacional (Bize, 2017).

En lo que se refiere específicamente a la microrregión forestal-cordillerana de Panguipulli, la inauguración de nuevos ramales de ferrocarriles (como la línea entre Lanco y Panguipulli), y el desarrollo del sistema de transporte por vapores ${ }^{7}$, tornaron aquellas tierras bastante rentables. Con esto, fue siendo generada una compleja y jerarquizada red de movimientos espaciales entre los núcleos productivos - destacando Neltume, donde además de aserraderos funcionaban la Fábrica de Terciados ${ }^{8}$ y la Industria Maderera S.A. (IMASA) ${ }^{9}-$, y los centros comerciales que controlaban la distribución, particularmente Panguipulli, el principal punto de contacto del lugar con

\footnotetext{
Sobre todo, entre los años 1930 y 1950, dentro del contexto de liberalismo pragmático y de transición hacia el modelo de sustitución de importaciones.

En 1943, CORFO inició un plan buscando modernizar la producción forestal-maderera, introduciendo nuevas formas de explotación del bosque y de nuevos usos de la madera (Guajardo, 2007).

6 EFE fue crucial para el desarrollo de la industria maderera regional, ya que, para lograr una explotación más racional de los bosques, y disminuir los costos de producción, era fundamental mejorar la capacidad de carga y la calidad del transporte. Además, la construcción y el mantenimiento de vías y estructuras de los ferrocarriles demandaban (en gran escala) maderas de calidad, especialmente el pellín, usado para la producción de durmientes.

Al permitir el transporte de maderas por flotación, mediante el arrastre por vapores - la presencia de los grandes lagos representaba una gran ventaja localizacional de la microrregión, potencializada con la llegada del ferrocarril. Esto estimuló inversiones privadas destinadas a adquirir nuevas tierras, bienes de capital, y construir infraestructuras espaciales.

8 La Fábrica de Terciados fue creada en 1942 por la Sociedad Agrícola y Maderera Neltume S.A. Esta fábrica funcionaba 24 horas por día, empleando a 500 obreros, con turnos que variaban entre 12 a 14 horas (Ruiz; Arrese \& Marchini, 2016).

IMASA producía puertas, ventanas, marcos y molduras. La industria contaba con avanzada tecnología y maquinaria de punta, lo que le permitía elaborar productos con mayor valor agregado (Bize, 2017).
} 
el resto del país. Estos flujos marcaron la geografía de la microrregión durante los tiempos de la explotación maderera, especialmente entre las décadas de 1940 y 1960.

Entonces, todo giraba en torno a la madera, e incluso las comunidades mapuches que no fueron expulsadas con el movimiento de expansión de la frontera capitalista, y lograron mantener el dominio sobre parte de su territorio ancestral ${ }^{10}$, pasaron a garantizar su reproducción social en función de la explotación capitalista del bosque (Comisión Verdad Histórica, 2008)ำ. Asimismo, el desarrollo de la industria forestal-maderera estimuló un fuerte flujo migratorio hacia la microrregión. En 1958 se estimaba la existencia de "unos seis mil o más obreros trabajando en las distintas faenas forestales" (Bize, 2017). Paulatinamente, esos trabajadores fueron adquiriendo conciencia de su condición de clase, hasta afirmarse como un actor político fundamental y protagónico de las grandes transformaciones sociales verificadas entre los años 1960 y 1970.

\section{Lucha obrera, estatización de la propiedad y construcción de un terri- torio popular en la cordillera: la experiencia del COFOMAP.}

Inserta dentro de un contexto de desarrollo desigual y contradictorio del capitalismo en el espacio rural regional, en el cual la territorialización del capitalismo monopolista ${ }^{12}$ se entremezclaba con características propias del latifundio, la historia de formación de la clase obrera local - forjada en condiciones de gran precariedad y de superexplotación de su mano de obra - ha estado marcada por una dinámica entre rebeldía y represión (Bize, 2017). Hasta mediados de los años 1960, los intentos de organización y movilización por derechos laborales y sociales fueron casi siempre reprimidos por los patrones (con el beneplácito del Estado), con acciones como despidos, persecuciones políticas, expulsiones de los fundos, etc. Sin embargo, la lucha obrera fue siendo fortalecida al acercarse a las corrientes vigentes en la izquierda chilena hacia el segundo tercio del siglo XX.

En Neltume, la experiencia de lucha acumulada por los trabajadores, y su creciente politización, favorecidos por una coyuntura histórica parcialmente favorable ${ }^{13}$, permitieron la creación, a fines de los años 1960, del Sindicato Industrial, Forestal y Maderero Neltume, que reunía a los obreros de IMASA, a los de la Fábrica de terciados, y a los llamados trabajadores de montaña ${ }^{14}$. Con la llegada de Salvador Allende al poder en 1970, y durante el corto tiempo que duró el gobierno de la Unidad Popular (UP), tanto el país como la microrregión experimentaron un período de gran agitación. En aquel momento, la lucha de los trabajadores de la madera entró en una nueva etapa, culminando con la creación, en octubre de 1971, del Complejo Forestal y Maderero de Pan-

\footnotetext{
10 Se estima que, a mediados de los años 1960, el territorio mapuche había sido reducido casi a quince por ciento de lo que era originalmente (Comité Memoria de Neltume, 2013).

11 Es el caso de la comunidad Juan Quintumán, a la que se confiere un Título de Merced en el año 1913, correspondiente a 743 hectáreas. Skewes et al. (2011) señalan que "tanto la venta de mano de obra como el arriendo de yuntas de bueyes para el traslado de la leña y una cierta abundancia de dinero, permitieron a la comunidad sortear una buena parte del siglo veinte" (p.45).

12 Según Umbelino de Oliveira (2007), el proceso de territorialización del capital monopolista en el campo se caracteriza, entre otras cosas, por el hecho de que el capitalista y el propietario de tierra pasan a configurar una sola figura, y por el predominio de las relaciones específicamente capitalistas de producción, es decir, el trabajo asalariado.

13 Especialmente debido a la promulgación de la ley no16.625 de Sindicalización Campesina, y al avance del proceso de reforma agraria promovido por el gobierno democratacristiano de Eduardo Frei Montalva.

14 Responsables por distintas faenas en los bosques, esos trabajadores eran los más precarizados de todos.
} 
guipulli (COFOMAP): potente empresa forestal estatal ligada a CORFO, surgida de la expropiación de 22 fundos ${ }^{15}$ y que ocupaba una superficie total de 304.739 hectáreas (FIGURA 01).

Figura 01

Mapa de la Microrregión forestal-cordillerana de Panguipulli, destacando las tierras que pertenecían al COFOMAP en 1972, durante el auge de su funcionamiento.

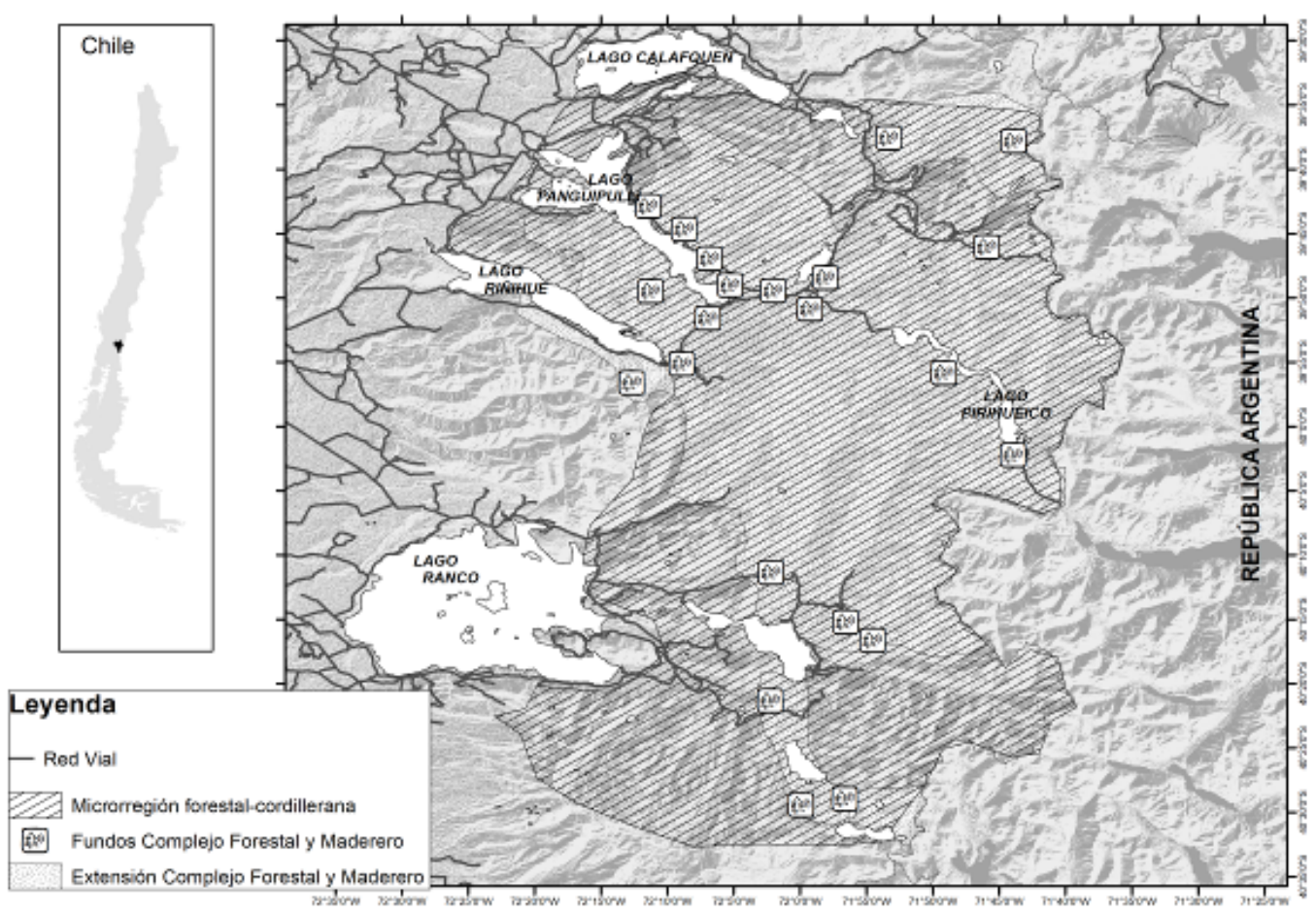

Fuente: Elaboración propia.

Administrada y operada por los propios trabajadores (en conjunto con representantes del gobierno), el COFOMAP cambió radicalmente la producción maderera microrregional, estableciendo nuevas relaciones sociales, económicas y laborales en la cordillera. El principal núcleo de este proyecto residía en Neltume. Ahí se concentraban las más importantes infraestructuras administrativas e industriales, y el $20 \%$ del total de trabajadores de la empresa. Desde este punto, y para él, se entrecruzaban los flujos espaciales estructuradores de la microrregión forestal-cordillerana de Panguipulli.

Asimismo, frente al crecimiento económico y demográfico que se esperaba alcanzar, fue diagnosticada la urgencia de invertir en la producción de un espacio que permitiera el establecimiento de conexiones más fluidas entre los diferentes sectores de la empresa y, entre estos y los centros de distribución y consumo. Para ello, fueron edificados nuevos caminos terrestres, así como ad-

Trafún, Paimún, Carranco, Releco, Puñir, Toledo, Paillahuinte, Molco, Chan Chan, Quechumalal, Enco, Mae, Neltume, Huilo Huilo, Pilamiquén, Pirihueico, Aruqihue, Maihue, Huieinahue, Riñinahue, Carrán y Caulle. 
quiridos medios de transporte y de comunicación. Además, había planes para la construcción de nuevas infraestructuras que deberían equipar el territorio, como núcleos residenciales, escuelas e institutos de formación técnica, hospitales, pequeñas centrales hidroeléctricas de paso, hoteles, criaderos (de ganado bovino y lechero), huertos, bosques reforestados, etc.

Al estatizar la propiedad de la tierra y democratizar las rentas que ella generaba, se ponía de manifiesto la función social del suelo, el valor de uso por sobre el valor de cambio. Con esto, se abría la brecha para proyectar una nueva configuración geográfica, diseñada desde abajo y condiciente con las necesidades de una sociedad que se encontraba en transición al socialismo.

En ese sentido, es posible pensar que el COFOMAP hizo de la microrregión forestal-cordillerana de Panguipulli un territorio popular, en el cual lo/as obrero/as, los/as campesino/as y los/las mapuches-huilliches trataban de ejercer soberanía y autonomía. Pero, como no podría dejar de ser, este proceso de territorialización del poder popular no estuvo libre de conflictos y de contradicciones, por el contrario [Klubock (2014); Ruiz, Arrese \& Marchini (2016); Bize (2017)]. Como un espejo de lo que se pasaba en Chile, las tensiones fueron sentidas simultáneamente en diferentes puntos y escalas, hasta que, en 1973, con el golpe civil-militar y la consecuente reorientación de la política económica chilena, la experiencia del COFOMAP fue llevada prematuramente a su fin.

\section{Dictadura y desposesión: abriendo el camino para la reterritorialización del capital en la cordillera austral chilena}

Dentro de un contexto dictatorial, la microrregión forestal-cordillerana de Panguipulli empezó a experimentar un nuevo proceso de reorganización territorial, movido por las nuevas necesidades despertadas con la neoliberalización de la economía nacional. Para ello, nuevos espacios de acumulación tuvieron que ser abiertos, de modo que el capital - en crisis - pudiera expandirse. Así, una nueva ronda de desposesión fue impuesta en la cordillera, destacando la privatización del COFOMAP.

A pesar de que había indicios de la privatización de la empresa desde el momento del golpe, inicialmente los militares decidieron mantenerla bajo tutela del Estado. Esta decisión fue tomada con base a un informe técnico Breve síntesis del Complejo Forestal y Maderero Panguipulli LTDA., de 1974. Dicho estudio destacaba, entre otras cosas, la existencia de una estructura orgánica manejable, así como un nivel de producción por sobre los niveles trazados para 1973. Además, resaltaba los programas productivos desarrollados en escala nacional y los alcances del programa agropecuario diseñado por los trabajadores, incluyendo la producción de alimentos y la creación ganadera (Ruiz; Arrese \& Marchini, 2016). Ahora bien, aunque siguiendo estatal, el proyecto original de una empresa pública del área social, cogestionada entre trabajadores y gobierno, y orientada hacia la construcción del socialismo, fue desconfigurado.

Y si en un primer momento se decidió mantener la empresa en las manos del Estado, después de 1975, esta situación empezaría a ser transformada, acompañando los cambios en la orientación de la política económica chilena (Gárate, 2012). A fines de los años 1970, COFOMAP se vio en serias dificultades financieras, sobre todo en función de las crecientes deudas acumuladas junto 
a CORFO ${ }^{16}$. Ahogada financieramente, la empresa que otrora había sido la grande impulsora del trabajo y del crecimiento económico microrregional, se redujo a una mera sombra de lo que fue un día ${ }^{17}$. Además, después de casi un siglo de superexplotación del bosque nativo, entraba en crisis el modelo productivo que históricamente no privilegió el manejo eficiente y sostenible, sino que la expansión hacia nuevas tierras. Esta situación sirvió para justificar la venta de la empresa, en un proceso que se extendió hasta fines de los años 1980.

A partir de entonces, la propiedad de la tierra se tornó altamente concentrada, siendo nuevamente dividida en grandes latifundios que quedaron en las manos de poquísimas personas. Como resultado, la cesantía y la pobreza se hicieron sentir por toda la cordillera, generando una grave crisis social que duró hasta por lo menos mediados de los años 1990. Entonces, muchas familias fueron obligadas a trasladarse, en virtud del avance de los cercos, del aumento de la represión ${ }^{18}$, y de la escasez laboral19.

Por su vez, la crisis despertó la necesidad de encontrar nuevas alternativas para dinamizar la economía microrregional y valorar aquellas tierras. Inicialmente, la respuesta fue buscada en la expansión de los monocultivos forestales de especies extranjeras y de crecimiento rápido. No obstante, los altos costos para reorganizar el sistema productivo y las dificultades para agilizar la circulación actuaron como factores limitantes. Ahora, si bien es cierto que dentro del modelo de explotación forestal que se estaba implementando en el país, las tierras cordilleranas no concurrían con las mismas ventajas competitivas que en otros momentos históricos (sobre todo porque tierras con mejores condiciones de situación y de ubicación fueron puestas a producir), sus características geográficas particulares permitirían otras formas de extracción de renta de la tierra.

La especificidad de la mercancía tierra en relación a las demás mercancías es justamente el hecho de que su valor de cambio no está asociado a un sólo valor de uso. Así, frente a las nuevas necesidades sociales y económicas engendradas a partir de los años 1990, las tierras cordilleranas se mostraron mucho más propicias a otros usos, potencialmente más rentables, dando lugar a una nueva etapa del desarrollo capitalista en el espacio rural microrregional.

16 En ese sentido, Alfaro (2016) explica que los préstamos que originalmente habían sido tomados como anticipos de capital, tuvieron su condición alterada en 1979, pasando a ser cobrados como prestamos de operación. Esto elevó el nivel de endeudamiento de la empresa, favoreciendo el proceso de liquidación de sus bienes y activos.

17 En el comienzo de la década de 1980, el Complejo Forestal Maderero Panguipulli empleaba a tan solo 241 trabajadores permanentes y otros 426 temporarios (Alfaro, 2016)

18 En el comienzo de la década de 1980, los habitantes de la microrregión asistieron a un recrudecimiento de la violencia del Estado, sobre todo después del intento de establecer una guerrilla en la cordillera, promovida por militantes políticos vinculados al MIR, que habían retornado clandestinamente a Chile con el objetivo de combatir la dictadura por medio de la lucha armada. La Guerrilla de Neltume, como quedó conocida, duró cerca de un año. Su acción fue rápidamente desarticulada por los militares que actuaron con violencia, incrementando las tácticas de amedrentamiento por parte del Estado hacia los habitantes y trabajadores de la cordillera. Sin duda, el aumento de la represión ayudó a debilitar cualquier posibilidad de resistencia frente a la venta de los predios y de la infraestructura del Complejo, a la pauperización y a la fragilización de la fuerza de trabajo, así como a la precarización de las condiciones de vida.

19 Ejemplo es la población Lolquellén, en Panguipulli, formada inicialmente por los habitantes que fueron expulsados del fundo Quechumalal. 


\section{La valoración del paisaje, y de la naturaleza conservada, y los cambios en la coherencia estructural de la Microrregión forestal-cordillerana de Panguipulli (1990 en adelante)}

La década de 1990 marca el inicio de una profunda transformación en la coherencia estructural de la microrregión forestal-cordillerana de Panguipulli. Portadora de mercancías que pasaron a ser bastante valoradas, como paisajes bucólicos y una naturaleza "exuberante", el espacio rural cordillerano microrregional viene cada vez más siendo reproducido como espacio de ocio. El resultado se materializa en una serie de infraestructuras funcionales a las actividades de consumo del y en el espacio ${ }^{20}$, como complejos turísticos, emprendimientos inmobiliarios y reservas de conservación. Este proceso de resignificación espacial ha servido para renovar, diversificar y potencializar las formas de extraer renta territorial, especialmente en lo que se refiere a la renta de monopolio.

La renta de monopolio, enseña Marx (2017), es aquella parte del lucro suplementar derivada del control exclusivo sobre una porción de la superficie terrestre, dotada de cualidades especiales y superiores, que permiten producir una mercancía única e irreproducible. El precio de monopolio es determinado por el deseo y por la capacidad de pago de los consumidores, y no depende del valor de los productos, o mismo del precio general de la producción (Oliveira, 2007).

Así, en un contexto de crisis ambiental y urbana, los paisajes cordilleranos, y el discurso construido en torno al bosque templado lluvioso valdiviano, vienen permitiendo a los propietarios de tierra extraer una variedad de formas de renta monopolista. El tipo de valoración que ellas promueven es de otro tipo en relación con el mercado inmobiliario strictu sensu. Su valor de uso reside en la representación y en la distinción (Arantes, 2012).

Entre las nuevas formas de renta monopolista posibilitadas por las tierras cordilleranas en el actual momento histórico, destacamos la renta del paisaje, la renta de la forma y la renta de la naturaleza conservada ${ }^{21}$. De modo resumido, la renta del paisaje es aquella extraída por medio de la privatización de los mejores ángulos y vistas de ciertos atractivos que antes eran comunes, tornándolos accesibles solamente a las personas que están dispuestas a pagar un precio de monopolio, que varía según la exclusividad y el grado de belleza proporcionado por cada pedazo de espacio.

Por su parte, la renta de la forma es generada a través de la construcción de formas únicas y espectaculares, que actúan dentro de la lógica de marca, creando un capital simbólico distintivo que conversa con el imaginario de los consumidores. Su producción es comandada por las ganancias provenientes de la divulgación mediática y de la capacidad de atraer riqueza (Arantes,

\footnotetext{
Siguiendo lo planteado por Ana Fani Alessandri Carlos (2001), el espacio turístico, al ser un lugar de acumulación articulado a las necesidades de reproducción de la sociedad, se relaciona directamente al consumo del espacio. Al mismo tiempo, se trata de un espacio volcado al consumo. Así, "las actividades producidas en el contexto del ocio señalan para la contradicción entre el espacio de consumo y el consumo del espacio" (p.71).

En este trabajo, se optó por utilizar el término conservacionismo, porque este supone el uso económico de la naturaleza, permitiendo el desarrollo de actividades económicas de carácter supuestamente sostenible, como por ejemplo el turismo. En ese sentido, el conservacionismo se diferencia del preservacionismo puro, "que pretende proteger la naturaleza contra el desarrollo moderno, industrial y urbano" (Diegues, 2001, p. 30).
} 
2012). Ya la renta de la naturaleza conservada se sustenta en el discurso de conservación del bosque nativo, y en la cantidad de biodiversidad existente por fracción de tierra. En otras palabras, cuanto más "natural" más valorado es. Como recuerda Harvey (1990), las ubicaciones de prestigio y status crean todos los tipos de posibilidades de realizar las rentas monopolistas de variadas facciones de la burguesía.

La propiedad privada permite acceder a esas nuevas rentas, que a menudo aparecen superpuestas: "La propiedad es una premisa histórica, y continúa siendo la base constante del modo de producción capitalista" (Marx, 2017: 677). Dado que las tierras de la microrregión se encuentran hoy concentradas en las manos de un reducido número de personas, las nuevas rentas monopolistas que la cordillera austral viene proporcionando están siendo disputadas y apropiadas de modo bastante desigual por los diferentes actores sociales presentes en el territorio.

La tendencia dominante apunta hacia una creciente centralización de esas rentas, al paso en que el territorio se torna cada vez más monopolizado. Es precisamente lo que ilustra el caso del eje que liga Neltume a Puerto Fuy. Ahí, donde antes se ubicaba el corazón de la actividad maderera industrial microrregional, funciona, actualmente, el más importante polo de desarrollo turístico-ecológico de la cordillera, teniendo como uno de sus principales motores la reserva biológica privada Huilo Huilo (FIGURA 02).

Figura 02

Mapa de los nuevos usos del espacio, derivados de la valoración de los atributos ecológicos y paisajísticos de la microrregión.

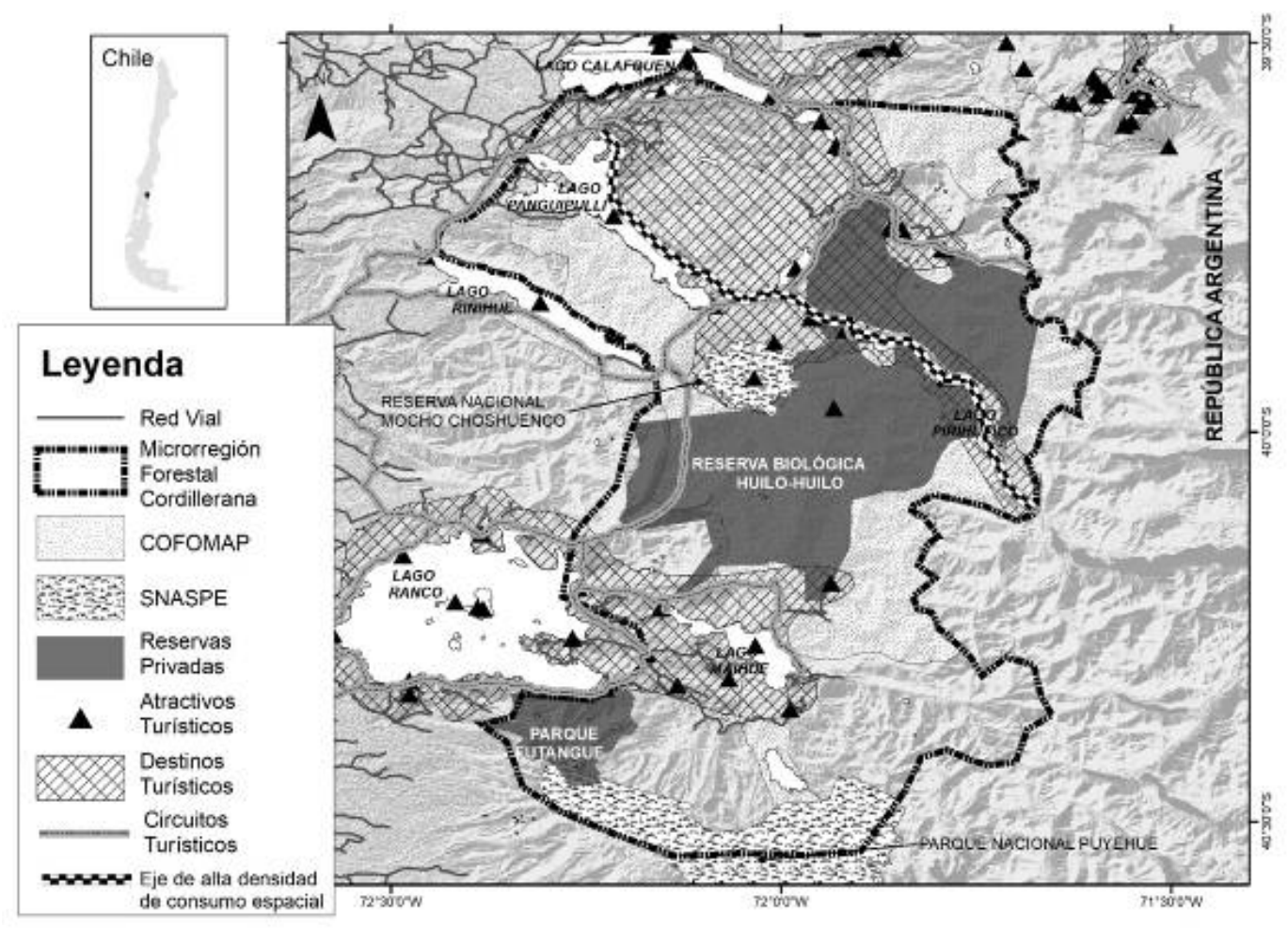

Fuente: Elaboración propia. 
Vinculada al grupo económico Themcorp ${ }^{22}$, la reserva biológica Huilo Huilo empezó a ser conformada a mediados de la década de 1990, siendo hoy considerada una de las áreas de conservación ambiental privadas más importantes y conocidas de todo el sur de Chile. Monopolizando más de cien mil hectáreas de tierras con gran potencial ecológico y turístico, el holding viene invirtiendo con fuerza en extraer al máximo las rentas generadas por las formas de ocio y de consumo del y en el espacio en la cordillera (FIGURA 03).

Como columna vertebral fue edificado un gran complejo turístico-hotelero, compuesto por variados tipos de alojamiento que van desde un refugio destinado a viajeros con menos recursos, hasta lujosas y espectaculares habitaciones, bastante más exclusivas. Valiéndose de un diseño futurista y a la vez orgánico, la forma arquitectónica de esas infraestructuras remite a un imaginario asociado a la fantasía y la ficción, ayudando a crear una marca distintiva, que diferencia a Huilo Huilo con otras áreas dedicadas a la conservación ambiental y al ecoturismo en sur del país. "La forma se convierte en capital por medio de la imagen, la cual es remunerada como capital simbólico, por una especie de renta de la forma" (Arantes, 2012: 35).

Figura 03

Instalaciones del hotel Nothofagus, ubicado dentro de la reserva privada/complejo turístico Huilo Huilo.

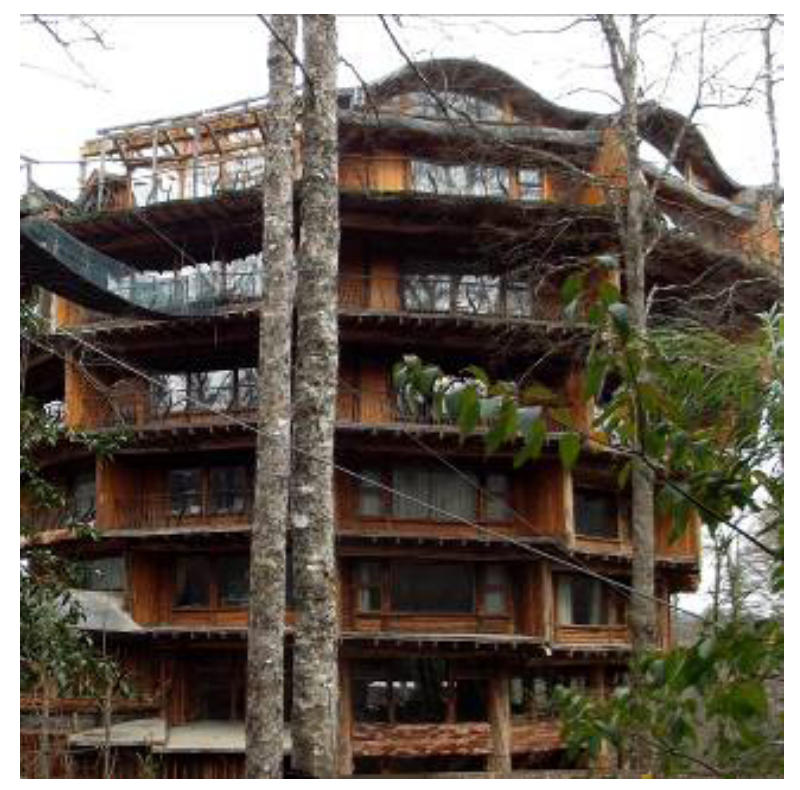

Fuente: autoría propia.

La reserva cuenta con dos centros de visita distintos, con atracciones que pueden ser conocidas en menos de un día, como los senderos auto guiados, criaderos de jabalíes y ciervos euro-

22 El Grupo es un holding que concentra diversas empresas que actúan en las más variadas áreas, destacando el desarrollo de tecnologías, productos y servicios volcados hacia la minería, a la construcción civil, y a la agricultura (fertilizantes), soluciones de higiene (veterinaria, industrial y de consumo masivo), además de la explotación forestal y de los negocios inmobiliarios y turísticos. Es en este rubro que entra Huilo Huilo (De Matheus, Zunino \& Huiliñir, 2018). 
peos, un teleférico que proporciona vistas privilegiadas de la reserva, cafés, tienda de souvenirs, restaurantes, cervecería artesanal y hasta un museo antropológico-geológico. Además, dentro de sus tierras, existe un loteo con parcelas destinadas a aquellas personas privilegiadas que desean - y pueden pagar por - adueñarse de un pedazo de tierra altamente valorado en función del discurso eco y del entorno verde proporcionado por la reserva.

Así, la reserva/complejo turístico-inmobiliario no solo monopoliza los valores de uso de calidad que hoy son considerados de calidad superior, como actúa para valorar las tierras ubicadas entre Choshuenco, Neltume y Puerto Fuy. Esto lleva a otra forma de extraer renta monopolística, derivada de la centralidad en relación a una actividad concentrada (Harvey, 2009). "La creación de espacios turísticos y del ocio a partir de nuevas estrategias interfiere en la producción de nuevas centralidades, en el sentido de que generan polos de atracción que redimensionan el flujo de personas en un espectro más amplio" (Carlos, 2001: 67).

Además, es preciso considerar que esas tierras disfrutan de una importante ventaja localizacional, debido a la cercanía y a las facilidades de acceso a centros urbanos regionales, como Valdivia y Temuco, y a destinos turísticos bastante consolidados en la cordillera andina austral, como Pucón, en la Araucanía chilena, y San Martin de los Andes y Bariloche, en el norte de la Patagonia Argentina ${ }^{23}$. Cabe mencionar también que la reserva se encuentra muy cercana del lago Pirihueico, que conecta - vía ferry - a Argentina, en medio a un escenario de gran atractivo estético ${ }^{24}$.

Justificado en términos de sustentabilidad y empleabilidad, este proceso de turistificación tiende a profundizar las contradicciones del espacio rural microrregional. En ese sentido, las posibilidades de apropiarse de las nuevas rentas generadas o potencializadas por la valoración de los atributos estéticos y ecológicos de la cordillera, estimularon la competencia intercapitalista por adueñarse de las tierras portadoras de algún tipo de valor de uso de calidad superior, como las que están ubicadas a las orillas de los lagos andinos (o que tienen buenas vistas hacia ellos), o aquellas que - contando con buenas vías de acceso - controlan algún tipo de atractivo turístico, como bosques conservados, ríos y cascadas.

Asimismo, recursos, accesos y bienes naturales que antes eran libres, pasan a ser cada vez más privados. El valor de cambio triunfa por sobre el valor de uso, "el espacio-mercancía se impone en la vida cotidiana como valor de cambio que somete el modo y el tiempo de uso" (Carlos, 2001: 70). Este proceso vino de la mano con la especulación inmobiliaria y con la reconcentración fundiaria.

En función de esto, mientras las nuevas rentas generadas vienen siendo apropiadas por un número reducido de individuos, el territorio se torna cada vez más monopolizado. Cabe recalar que esta monopolización no se da solo en términos de apropiación de las tierras y de los recursos, sino también en términos de la creación y reproducción de un discurso ideológico único, que justifica y sustenta este proceso.

\footnotetext{
${ }^{23}$ Recientemente, las ventajas proporcionadas por la situación geográfica de esas tierras fueron potencializadas aún más, debido a las inversiones públicas realizadas en infraestructuras de capital fijo de circulación, como el mejoramiento de la ruta 203 CH, la modernización del complejo fronterizo Hua Hum, la adquisición de una nueva barcaza para transporte de pasajeros y las reformas efectuadas en el embarcadero de Puerto Fuy.

24 Hasta el final de esta investigación, la concesión publica del servicio de transporte fluvial se encontraba en las manos del grupo Themcorp.
} 
Ahora bien, como el capital se reproduce de modo contradictorio, la valoración de las particularidades ecológicas y paisajísticas de la cordillera - aunque sirva como base para renovar las condiciones de la acumulación - también abre pequeñas fisuras, que bien pueden ser aprovechadas en favor de los intereses de los actores sociales no hegemónicos.

En este sentido, vemos el establecimiento de iniciativas de turismo de base local y comunitaria que involucran a campesinos y comunidades indígenas "que ven la posibilidad de conservar su identidad y naturaleza por medio de una actividad complementaria a los distintos papeles que deben atender en su tiempo de vida" (Henríquez \& Pacheco, 2016: 47). Al mismo tiempo, asistimos al surgimiento de pequeños negocios como restaurantes y quioscos familiares, campings, tiendas de artesanías y cabañas, que permiten a los habitantes de la microrregión apropiarse de al menos parte de las nuevas rentas generadas por el consumo del y en el espacio, especialmente durante los meses estivales.

Y aunque es cierto que el actual proceso de turistificación del espacio busca crear y reproducir la imagen de un lugar prístino, esterilizado y espectacular, no es posible borrar las marcas de lucha, emancipación y desposesión, que están presentes en la memoria social y espacial de la microrregión, poblando el imaginario colectivo y el paisaje geográfico de la cordillera.

En este sentido, la estatua erigida en homenaje a los trabajadores del Complejo muertos y/o desaparecidos durante la dictadura, invita a los que pasan por la localidad a mirar la cordillera con otros ojos. Lo mismo pasa con el Museo de la Memoria de Neltume: especie de punto heterotópico que, funcionando donde antes era una de las casas patronales del antiguo pueblo maderero, se aprovecha del aumento del flujo turístico generado por la reserva, para ofrecer a los visitantes la perspectiva histórico-geográfica de los trabajadores de la madera - sujetos activos y altivos de la historia, responsables por construir en la cordillera un territorio popular que, a pesar de masacrado, no fue olvidado.

\section{Consideraciones finales}

La región no es una configuración espacial estática, que existe a priori y permanece inerte a lo largo de la historia. El recorte espacial que ha sido delimitado y estudiado en esta ocasión da cuenta del dinamismo que subyace a este concepto. En ese sentido, el avance capitalista sobre antiguos territorios mapuches ocurrido a partir de fines del siglo XIX, dio lugar a la producción de una organización espacial cuya estructura, movimiento y funcionalidad pasaron a ser determinados por la explotación de la madera del bosque nativo, dentro del régimen de propiedad privada. Durante la primera mitad del siglo XX, la industria forestal-maderera se consolido en aquel lugar, entregando forma a lo que aquí llamamos de microrregión forestal-cordillerana de Panguipulli.

Entre los años 1960 y 1970, la microrregión fue palco de intensas movilizaciones y luchas sociales, que resultaron en la creación de un enorme territorio popular, cuyo motor era el Complejo Forestal maderero Panguipulli (COFOMAP) - empresa pública cogestionada entre trabajadores y el Estado. Con el golpe cívico-militar de 1973, la experiencia fue llevada a su fin. Variados mecanismos de acumulación por desposesión (como la privatización de los bienes públicos y de los recursos naturales, la reconcentración fundiaria, etc.) fueron puestos en marcha entre mediados 
de los años 1970 y fines de los años 1980, abriendo el camino para la más reciente etapa del desarrollo capitalista microrregional, iniciada en los años 1990.

Dentro de una nueva configuración social, política y económica inaugurada en aquel momento, las tierras cordilleranas ganaron otros usos y significados, siendo valoradas en función de los atributos estéticos y ecológicos del bosque nativo y de la cordillera andina austral. Así, el lugar que nació del despojo de las poblaciones originarias, y creció en función de la actividad maderera, se ve transformado en una nueva frontera para la expansión capitalista, ahora sustentada por la explotación del paisaje y del discurso ecológico.

Con esto, nuevas estructuras y flujos se materializaron en el paisaje, derivados y a la vez funcionales al desarrollo de las actividades y negocios ligados al consumo del y en el espacio. Es precisamente el caso del eje que liga Panguipulli a Puerto Fuy, donde la reserva/complejo turístico-inmobiliario Huilo Huilo se firma como una nueva centralidad, actuando como un agente catalizador para el establecimiento de nuevos flujos, para la valoración de las tierras que le están cercanas, y para la resignificación de aquel lugar que, de ser el más importante cordón de la actividad industrial, se transforma actualmente en el principal polo de atracción turística microrregional.

De la explotación forestal a la explotación del paisaje, este viene siendo el movimiento que moldea la coherencia estructural de la microrregión en la actualidad. Y una vez circunscrito dentro de los límites del capital, este proceso, si bien diversifica las posibilidades de extracción de rentas territoriales, camina en dirección a la privatización de los recursos y de los bienes públicos, a la espectacularización y fetichización del paisaje, así como, la homogeneidad de los espacios turísticos y a la monopolización del territorio.

\section{Bibliografía}

ALFARO, K. Acumulación por desposesión en Chile: el caso del Complejo Forestal y Maderero Panguipulli en sur de Chile (1973-1990). Revista História 396, 2016, nº 02, p.229-255. Disponible en internet: http://www.historia396.cl/index.php/historia396/article/view/90

ARANTES, P. F. Arquitetura na era digital-financeira: desenho, canteiro e renda da forma. São Paulo: editora 34, 2012.

BIZE, C. El otoño de los raulíes: poder popular en el Complejo Forestal y maderero Panguipulli (Neltume, 1967-1973). Santiago: Tiempos robados, 2017.

CARLOS, A.F. "Novas" contradições do espaço. En: DAMIANI, A. L.; CARLOS, A. F.; C. A SEABRA, O. (orgs.). O espaço no fim do século: a nova raridade. São Paulo: Contexto, 2001, p.62-74.

CARDYN, P. Sangre de Baguales: epopeyas mapuches y obreras en tiempos del Complejo Maderero Panguipulli. Santiago de Chile: LOM, 2017.

COMITÉ MEMORIA NELTUME. Guerrilla en Neltume: una historia de lucha y resistencia en el sur de Chile. Santiago de Chile: LOM, 2013. 
COMISION VERDAD HISTÓRICA Y NUEVO TRATO CON LOS PUEBLOS INDÍGENAS. Informe de la Comision Verdad Historica y Nuevo Trato con los Pueblos Indígenas. Santiago de Chile: Comisionado Presidencial para Asuntos Indígenas, 2008. Disponible en internet: http://www.memoriachilena.cl/602/articles-122901_recurso_2.pdf

CORRÊA, R.L. Região e Organização Espacial. São Paulo: Editora Ática, 2003.

DE MATHEUS, L. F. Desposeer para acumular: reflexiones sobre las contradicciones del proceso de modernización neoliberal de la agricultura chilena. Revista Mundo Agrario. vol. 17, n 34, 2016. Disponible en internet: https://www.mundoagrario.unlp.edu.ar/issue/view/280

DE MATHEUS, L. F.; ZUNINO, H.; HUILIÑIR, V. El negocio de la conservación ambiental: cómo la naturaleza se ha convertido en una nueva estrategia de acumulación capitalista en la zona andino-lacustre de Los Ríos, sur de Chile. Revista Scripta, Vol. 22, n 583, 2018. Disponible em internet: http://revistes.ub.edu/index.php/ScriptaNova/article/view/19021/23240

DIEGUES, A.C. O mito moderno da natureza intocada. São Paulo: Hucitec, 2001

FARRIS, M.; MARTINEZ, O. El capitalismo del holding transnacional en el sector forestal chileno: la consolidación de una hegemonía territorial. Izquierdas, 45, 2019, p. 23-50

GÁRATE, M. La revolución capitalista de Chile (1973-2003). Santiago de Chile: Ediciones Alberto Hurtado, 2012.

GUAJARDO, G. Tecnología, Estado y Ferrocarriles en Chile, 1850-1950. D.F. México: Fundación Ferrocarriles Españoles, 2017. Disponible en internet: http://www.memoriachilena.cl/archivos2/pdfs/ MC0062438.pdf

HAESBAERT, R. Região, regionalização e regionalidade: questões contemporâneas. Antares, $\mathrm{n}^{\circ}$ 3, 2010. Disponible en internet: http://www.ucs.br/etc/revistas/index.php/antares/article/view/416

HARVEY, D. Los límites del capitalismo y la teoría marxista. D.F. México: FCE, 1990.

HARVEY, D. El nuevo imperialismo Madrid: Akal, 2004.

HARVEY, D. Espacios del capital. Madrid: Akal, 2009.

HUILIÑIR, V; ZUNINO, H; DE MATHEUS, L. F. Exclusión y desigualdad en localidades próximas a las Reserva Ecológica Privada Huilo Huilo en el sur de Chile. ACME (An International Journal for Critical Geographies), V. 18, n02, 2019.

KATZ, C. Whose nature, whose culture? (private productions of space and the "preservation" of nature). En: BRAUN, B.; CASTREE, N. (eds.). Remaking Reality. London; New York: Routledge, 1998, p.46-63. 
KLUBOCK, T. La frontera: forests and ecological conflict in Chile's Frontier territory. Durham/London: Duke University press Books, 2014.

LEFEBVRE, E. A Revolução Urbana. Belo Horizonte: UFMG, 2004.

MARX, K. O Capital - livro I. São Paulo: Boitempo, 2013.

MARX, K. O Capital - livro III. São Paulo: Boitempo, 2017.

MASSEY, D. Regionalism: some current issues. Capital and Class Review, 1978, nº 06, p. 106-125.

MOREIRA, R. Renda da natureza e territorialização do capital: reinterpretando a renda da terra na competição intercapitalista. Revista Estudos Sociedade e Agricultura, nº4, 1995, p. 89-111. Disponible en internet: https://revistaesa.com/ojs/index.php/esa/article/view/60/61

PACHECO, G.; HENRÍQUEZ, C. El turismo de base comunitaria y los procesos de gobernanza en la comuna de Panguipulli, sur de Chile. Gestión Turística, 2016, n²5, p. 42-62. Disponible en internet: http://revistas.uach.cl/index.php/gestur/article/view/1708

RUIZ, J.; ARRESE, M.; MARCHINI, F. Antecedentes históricos sobre el Complejo Histórico Maderero Panguipulli, provincia de Valdivia, centro-sur de Chile. Revista Bosque, 2016, n 37, p.473-484. Disponible en internet: https://scielo.conicyt.cl/pdf/bosque/v37n3/art04.pdf

SANTOS, M. A natureza do espaço. São Paulo: Edusp, 2002.

SKEWES, J. C.; GUERRA, D.; ROJAS, P.; MELLADO, M. A. ¿La memoria de los paisajes o los paisajes de la memoria? Los enigmas de la sustentabilidad socioambiental en las geografías en disputa. Revista Desenvolvimento e Meio Ambiente, 2011, n. 23, p.39-57. Disponible en internet: http:// revistas.ufpr.br/made/article/download/20774/14454

SMITH, N. Uneven Development. London; New York: Verso, 2010.

OLIVEIRA, A. Modo capitalista de produção, agricultura e reforma agrária. São Paulo: FFLCH-USP, 2007. Disponible en internet: http://www.gesp.fflch.usp.br/sites/gesp.fflch.usp.br/files/modo_capitalista.pdf 
